\title{
IMPLICAÇÕES JURÍDICAS DO ERRO PROFISSIONAL: A RESPONSABILIDADE CIVIL DO CIRURGIÃO-DENTISTA
}

\author{
Aline Alexsandra da Silva REIS ${ }^{1}$ \\ Carlos Eduardo Ferreira REIS ${ }^{2}$ \\ Maria Élida Santos SÁ \\ ${ }^{1}$ Advogada. Graduada pela ESUV. Especialista em Direito Público. Especialista em Direito e Processo do Trabalho. \\ ${ }^{2}$ Cirurgião-dentista graduado pela UninCor. Especialista em Odontologia Legal. Especialista em Periodontia. \\ ${ }^{3}$ Cirurgiã-dentista graduada pela Unit. Especialista em Endodontia.
}

Recebido em: 09/09/2013 - Aprovado em: 13/12/2013 - Disponibilizado em: 15/01/2014

Resumo: O presente trabalho tem por escopo, adentrar na perspectiva jurídica de consequente imputação a erros na área odontológica, divisando e caracterizando sua responsabilização civil frente às inovadoras disposições abarcadas, mormente, pelo Código de Defesa do Consumidor. Tal assertiva, porém, justifica-se ante o crescente número de demandas judiciais e sobejos questionamentos concernentes ao cirurgião-dentista como prestador de serviços. Buscouse, através da revisão da literatura, trazer à baila as espécies de responsabilidade civil do cirurgião-dentista bem como as consequências advindas de seu eventual insucesso terapêutico.

Palavras-chave: Responsabilidade civil. Cirurgião-dentista. Erro profissional. Implicações jurídicas.

Abstract: The present work aims to enter in the legal perspective of the imputation errors in dental area, descrying and characterizing its civil liability according to the innovative provisions clasped, particularly by the Consumer Defense Code. This assertion, however, is justified with the increasing number of lawsuits and excessive questions concerning the dentist as a service provider. Was sought through literature review, to come up for discussion the species of liability of the dentist as well as the consequences resulting from its eventual treatment failure.

Keywords: Civil liability. Surgeon-dentist. Malpractice. Legal implications.

\section{Introdução}

A responsabilidade civil advém da agressão a um interesse jurídico em decorrência do descumprimento de uma norma jurídica preexistente. Destarte, visando assegurar e tutelar o regular desenvolvimento dos atos jurídicos, emerge o referido instituto, revestindo-se de um caráter repressivo através do qual todo aquele que causar danos materiais, morais ou quaisquer outras espécies de dano, obriga-se a repará-los perante terceiros potencialmente prejudicados.

Neste ínterim, importante destacar alguns conceitos abarcados pela doutrina.

Nos dizeres de Diniz (2004), a responsabilidade civil pode ser definida como a aplicação de medidas que obriguem uma pessoa a reparar dano moral ou patrimonial causado a terceiros, em razão de ato por ela mesma praticado, por pessoa por quem ela 
responde, por alguma coisa a ela pertencente ou de simples imposição legal.

Para Cavalieri Filho (2010), o sentido etimológico, de responsabilidade exprime a ideia de obrigação, encargo, contraprestação. Em sentido jurídico, o vocábulo designa o dever de alguém que tem de reparar o prejuízo decorrente da violação de um outro dever jurídico. Em síntese, responsabilidade civil é um dever jurídico sucessivo que surge para recompor o dano decorrente da violação de um dever jurídico originário.

Gonçalves (2010) afirma que toda atividade que acarreta prejuízo traz em seu bojo, como fato social, o problema da responsabilidade. Objetiva-se restaurar o equilíbrio moral e patrimonial provocado pelo autor do dano.

Por derradeiro, importante destacar a perspectiva de Aquino (2009) que expressa o dever de responder por dano material e/ou moral causado a terceiro por atos comissivos ou omissivos. A responsabilidade por dano material pode ficar circunscrita a uma pena pecuniária imposta ao agressor, alternativa ou cumulativa com a reparação da lesão causada, a cargo ou às expensas do causador. Já no que se refere à reparação pelo dano moral, cumpre determinar um valor monetário que possa, além de quantificar o sofrimento gerado, desestimular sua repetição. Na área de saúde a maioria das causas levadas ao judiciário está baseada em dano moral cumulado com dano material.

Desse modo, infere-se dos conceitos supramencionados, que a responsabilidade pressupõe um dever jurídico precedente. Portanto, é imperioso reconhecer que toda conduta humana que viole dever jurídico originário e cause consequente prejuízo a outrem é fonte geradora de responsabilidade civil, respondendo, seus autores, pelas condutas lesivas a eles imputadas.

\section{Pressupostos da responsabilidade civil}

Para que haja responsabilização civil, ou seja, obrigação de indenizar por parte do profissional responsável, necessário se faz a presença de pressupostos legais sem os quais não é possível aferi-la, sendo eles: ação ou omissão do agente, o dano, o nexo de causalidade, e a presença ou não de culpa ou dolo.

\section{Ação ou omissão do agente}

Pode ser conceituada como sendo o ato humano, comissivo ou omissivo, ilícito ou lícito, voluntário e objetivamente imputável, do próprio agente ou de terceiro, que cause dano a outrem, gerando o dever de reparar os direitos do lesado. 
Segundo Cavalieri Filho, (2010) a ação é forma mais comum de exteriorização da conduta. Consiste, pois, a ação em um movimento corpóreo comissivo, um comportamento positivo, como a destruição de uma coisa alheia, a morte ou lesão corporal causada a alguém, e assim por diante. Já a omissão, forma menos comum de comportamento, caracteriza-se pela inatividade, abstenção de alguma conduta devida.

Para que se configure a responsabilidade por omissão é necessário que exista o dever jurídico de praticar determinado fato (de não se omitir) e que se demonstre que, com sua prática, o dano poderia ter sido evitado (Gonçalves, 2010).

$\mathrm{O}$ ato de vontade, em sede de responsabilidade civil, deve ser contrário ao ordenamento jurídico. Importa ressaltar, contudo, que voluntariedade significa pura e simplesmente o discernimento, a consciência da ação, e não a consciência de causar um resultado danoso. Sendo assim, a voluntariedade deve estar presente tanto na responsabilidade civil subjetiva quanto na responsabilidade objetiva.

\section{Dano}

Nas lições de Cavalieri Filho (2010), o dano é, sem dúvida, o ponto mais importante da responsabilidade civil. Não haveria que se falar em indenização, nem em ressarcimento, se não houvesse o dano. Pode haver responsabilidade sem culpa, mas não pode haver responsabilidade sem dano.

Para Stoco (2007) o dano é, pois, elemento essencial e indispensável à responsabilização do agente, seja essa obrigação originada de ato ilícito ou de inadimplemento contratual, independente, ainda, de se tratar de responsabilidade objetiva ou subjetiva.

Ante o exposto acima, pode-se afirmar que não há responsabilidade civil sem dano, que deve ser certo e concreto.

A Constituição Federal de 1988 assegurou em seu art. $5^{\circ}$, indenização tanto pelo dano material como o moral decorrente de sua violação. Em suma, dano é lesão de um bem jurídico, tanto patrimonial como moral, surgindo então a dicotomia do dano em extrapatrimonial (moral) e patrimonial (material) .

\section{Dano moral}

Dano moral é aquele que atinge a pessoa em seus direitos da personalidade como a honra, a dignidade, a imagem, a intimidade e o nome, podendo causar à vítima dor, tristeza, angústia, sofrimento ou humilhação.

O dano moral é também tido como extrapatrimonial, isto porque, consiste em dano cuja razão primordial é o abalo à esfera 
moral, ou seja, não inerente à seara patrimonial.

Inobstante, não importa dizer, que todo e qualquer aborrecimento será hábil a caracterizar o referido dano.

Nesse ínterim, importante salientar o enunciado 159 da III Jornada de Direito Civil: 159 - Art. 186: O dano moral, assim compreendido todo dano extrapatrimonial, não se caracteriza quando há mero aborrecimento inerente à prejuízo patrimonial.

Cavalieri Filho (2010) assevera que dano moral, à luz da Constituição vigente, nada mais é do que uma agressão à dignidade humana. Nessa linha de princípio, só deve ser reputado como dano moral a dor, vexame, sofrimento ou humilhação, que fugindo à normalidade, interfira intensamente no comportamento psicológico do indivíduo, causando-lhe aflições, angústias e desequilíbrio em seu bem-estar. Mero dissabor, aborrecimento, mágoa, irritação ou sensibilidade exacerbada estão fora da órbita do dano moral, porquanto além de fazerem parte da normalidade do nosso dia a dia, tais situações não são intensas e duradouras, a ponto de romper o equilíbrio psicológico do indivíduo. Se assim não se entender, acabaremos por banalizar o dano moral, ensejando ações judiciais em busca de indenizações pelos mais triviais aborrecimentos.

\section{Dano material}

O dano material consiste na lesão concreta que atinge interesses relativos a um patrimônio, acarretando sua perda total ou parcial.

Assim, na lição de Cavalieri Filho (2010), o dano patrimonial, também chamado de dano material, atinge os bens integrantes do patrimônio da vítima, entendendo-se como tal o conjunto de relações jurídicas de uma pessoa apreciáveis economicamente.

Destarte, insta salientar que tornouse indiscutível a cumulatividade do dano moral com o material, o que culminou na edição da súmula 37 pelo Superior Tribunal de Justiça, que assim dispõe: "São cumuláveis as indenizações por dano material e dano moral, oriundos do mesmo fato".

\section{Nexo de causalidade}

O nexo de causalidade é a relação de causa e efeito entre a conduta praticada e o resultado. Para que se caracterize a responsabilidade civil do agente, não basta que ele tenha praticado uma conduta ilícita, e nem mesmo que a vítima tenha sofrido o dano. É imperioso que o dano tenha sido causado pela conduta ilícita do agente e que exista uma necessária relação de causa e efeito. 
Gonçalves (2010) assevera que deve haver um nexo causal entre a ação ou omissão do agente e o dano verificado. Sem esse nexo causal não existe a obrigação de indenizar. Se houve o dano, mas sua causa não está relacionada com o comportamento do agente, inexiste a relação de causalidade e, também, a obrigação de indenizar.

Enfim, nexo causal é o vínculo existente entre o agente e o resultado danoso sem o qual não há como se caracterizar a responsabilidade civil.

\section{Culpa}

A culpa, assim como os demais pressupostos citados alhures, afigura-se imprescindível para caracterização e eventual ressarcimento pelos danos causados.

Para Cavalieri Filho (2010) a noção de culpa, em sentido amplo (lato sensu) abrange toda espécie de comportamento contrário ao Direito, seja intencional, como no caso de dolo; ou tencional, como na culpa. No dolo o agente quer a ação e o resultado, ao passo que na culpa ele só quer a ação, vindo a atingir o resultado por desvio acidental de conduta decorrente de falta de cuidado.

O dolo é a pretensão consciente de transgredir o direito, orientada à consecução do fim ilícito, e a culpa compreende a imprudência, a imperícia e a negligência (Diniz, 2004).

\section{Responsabilidade civil do cirurgião- dentista}

A responsabilidade civil é um tema palpitante no Direito brasileiro. Isso ocorre em função dos inúmeros e relevantes avanços atinentes à legislação, com grande modificação no reconhecimento do povo como cidadão, principalmente com a Constituição da República Federativa do Brasil, de 1988, que instituiu, além de outras garantias, o direito à saúde.

Consequentemente, houve um grande aumento do número de ações indenizatórias a fim de reparar os danos causados por profissionais da saúde.

Não obstante, com o advento da Lei $n^{\circ}$. 8078, de 11 de setembro de 1990, (Código de Defesa do Consumidor), o cirurgião-dentista passou a ser considerado fornecedor de serviços. Isso acirrou os debates sobre a questão, bem como elevou o número de casos levados ao Poder Judiciário, no sentido de ressarcimento de danos por erro profissional (Dias Ribeiro, 1996).

O Código de Defesa do Consumidor define serviço como "qualquer atividade fornecida no mercado de consumo mediante remuneração", estando a atuação do cirurgiãodentista sujeita a tal regulamentação também (Souza, 2000).

Tais danos são obrigações derivadas de atos ilícitos por meio de ações, culposas ou 
dolosas, praticadas como infração a uma conduta a ser seguida (Félix, 2001).

Assim, de acordo com o artigo 927 do Código Civil Brasileiro (2002), aquele que por ato ilícito causar dano a outrem fica obrigado a repará-lo.

Segundo Caixeta (2008), ato ilícito odontológico é o ato comissivo ou omissivo que praticado pelo profissional da Odontologia abre possibilidade de dano para o paciente em virtude da falta de diligência do profissional, entendendo-se que o mesmo poderia ou deveria ter atuado de outro modo no caso concreto.

Imperioso frisar, que um ato ilícito odontológico se dá mesmo quando a conduta do profissional seja involuntária, vez que resulta de imperícia (quando o cirurgião dentista, sem a devida qualificação técnica, ou seja, sem os conhecimentos necessários para desenvolver tal intervenção faz $\mathrm{o}$ atendimento fora do ramo de sua competência causando dano), imprudência (caracterizada pela atuação precipitada, de maneira intempestiva e sem se preocupar com os resultados adversos e nocivos que aquela conduta sem os devidos cuidados poderá causar) ou negligência (entendida como descuido, falta de atenção, omissão displicente, podendo ser entendida como a falta de cuidados e precauções que a profissão exige).

Pereira (2005) exemplifica que o cirurgião-dentista ao elaborar um diagnóstico deverá estruturar um prontuário completo do paciente, com os exames complementares, quando necessário, exame físico geral e bucal, além de ter de realizar uma avaliação chamada anamnésica, na qual é realizado um questionário inquirindo ao paciente todas suas condições físicas e psíquicas que possivelmente poderia interferir no tratamento, desde uma alergia a um determinado tipo de medicamento ou anestesia até a presença de doenças infecto contagiosas que exigiriam maiores cuidados do dentista responsável. Depois de realizados essa etapa inicial, realiza-se um diagnóstico final da situação em que se encontra o paciente e determinam-se quais serão as necessidades de tratamento desse paciente, que deverá fazer parte do plano de tratamento, indicando para ele qual é o prognóstico, ou seja, como será o possível resultado após a realização da terapêutica.

\section{Obrigação de meio e de resultado}

Segundo Antunes (2001) a
principal diferença que existe entre a
obrigação de resultado e a de meio, é que na
primeira, o profissional está automaticamente
assumindo a responsabilidade de atingir e
conseguir um determinado resultado eficiente,
preestabelecido com o tratamento proposto. E
caso este resultado não seja convenientemente
obtido, caberia ao paciente o direito de
recurso ou ação contra o profissional.


Segundo Cavalieri Filho (2010) e Gonçalves (2010), embora em alguns casos se possa dizer que a obrigação dos cirurgiões dentistas é de meio, a maioria das vezes apresenta-se como de resultado. Isto porque os processos de tratamento dentário são mais regulares, específicos, e os problemas menos complexos.

Ademais, é mais frequente nessa área a preocupação com a estética, consequentemente, quando o cliente manifesta interesse pela colocação de aparelho corretivo dos dentes, de coroas de porcelana e, modernamente, pelo implante de dentes, está em busca de um resultado, não lhe bastando mera obrigação de meio (Cavalieri Filho, 2010).

Assim, a diferença que existe entre a obrigação de meio e a de resultado, é que na primeira o profissional não se responsabiliza e não tem como prever como será o resultado final do tratamento, pois ele pode variar de acordo como o organismo de cada paciente. Porém, caso seja previsível o resultado, ou se o dentista prometer ao paciente uma possibilidade de resultado ele deverá cumprir sob pena de ter que indenizar o dano e/ou a insatisfação do paciente. Nessa modalidade de obrigação de resultado o cirurgião-dentista está automaticamente assumindo a responsabilidade de atingir e alcançar uma expectativa dada ao seu cliente, que normalmente, fica preestabelecido no plano de tratamento proposto. Se o paciente entender que o resultado obtido não atingiu e não coincidiu com aquele anunciado pelo dentista, ele poderá levar seu caso para decisão em uma lide judicial. É relevante destacar que na obrigação de meio conforme relatado anteriormente, não há como se prever o resultado, mas não exime o dentista de empregar todos meios necessários para a cura ou solução do problema, apesar de não poder assumir a responsabilidade quanto ao desenvolvimento final do tratamento. Contudo, ele deverá utilizar-se de todos os meios e recursos disponíveis para conseguir o melhor resultado possível para a saúde dos seus pacientes. Não ocorre uma unanimidade de opinião entre as manifestações de legisladores e juristas se a atividade de cirurgião-dentista deve ser classificada como de resultado ou de meio. Mas a grande parte dos nossos juristas entende que ao contrário dos procedimentos do campo da medicina, para maior parte dos tratamentos odontológicos, é possível prever um resultado final (Pereira, 2005).

Nas lições de Nelson Nery Jr, (apud Calvielli, 1997), quando a obrigação do profissional liberal, ainda que escolhido intuitu personae pelo consumidor, for de resultado, sua responsabilidade pelo acidente de consumo ou vício de serviço é objetiva. Ao revés, quando se tratar de obrigação de meio, aplica-se o $\$ 4^{\circ}$ do Art. 14 do Código de Defesa do Consumidor em sua inteireza, devendo ser examinada a responsabilidade do 
profissional sob a teoria da culpa. De todo modo, nas ações de indenização movidas em face do profissional liberal, quer se trate de obrigação de meio ou de resultado (objetiva ou subjetiva), é possível haver inversão do ônus da prova em favor do consumidor, conforme autoriza o Art. $6^{\circ}$, VIII, do referido Código.

No tocante à caracterização de obrigação de meio por especialidades odontológicas, Venosa (2004) citou as seguintes especialidades como sendo de obrigação de meio, ou seja, que não admitem que se assegure resultado: Traumatologia Buco-maxilo-facial, Endodontia, Periodontia, Odontopediatria e Ortodontia.

Consoante entendimento de Kfouri Neto (2003), tem-se como obrigações de resultado o clareamento dental, a odontologia preventiva e a radiologia.

No que tange especificamente ao tratamento ortodôntico, embora haja uma tendência dos juristas de o considerarem como obrigação de resultado, existe uma grande divergência em torno do tema, porquanto o assunto ainda não se encontra devidamente pacificado na doutrina.

\section{Excludentes de responsabilidade}

Importa consignar que mesmo tendo ocorrido um resultado que não tenha sido o previsto pelo paciente, o cirurgião dentista, ainda assim, poderá ser isentado da devida reparação.

Consoante entendimento doutrinário, alguns fatores, portanto, podem interromper a cadeia causal, desobrigando o agente do dever de indenizar. São as denominadas excludentes de responsabilidade, sendo elas: o estado de necessidade, a legítima defesa, a culpa da vítima, o fato de terceiro, a cláusula de indenizar e o caso fortuito ou força maior. (Oliveira, 1999).

\section{Considerações finais}

À guisa de conclusão, não se constatou na doutrina e tampouco na jurisprudência uma unanimidade de opinião no que concerne à responsabilidade civil do cirurgião-dentista. Nem os legisladores nem os juristas chegaram a um consenso se a profissão de cirurgião-dentista o remete a uma obrigação de meio ou de resultado. Hodiernamente, considerável parcela dos juristas preceitua que o cirurgião-dentista diferentemente do médico, tem obrigação de resultado, porquanto, na maioria dos tratamentos odontológicos é possível se prever um resultado final, muito embora, haja nesse desiderato, questões intrinsecamente imbricadas que demandariam melhor reflexão. Desta forma, implica afirmar que os tratamentos dentários teriam como regra geral o comprometimento com o resultado final, 
ficando o cirurgião-dentista responsável por além de empregar todos os recursos disponíveis, alcançar o resultado almejado pelo seu paciente. Em suma, apesar de na maioria das decisões judiciais ter-se observado a tendência de obrigação de resultado pelo cirurgião-dentista, é salutar avaliar o caso concreto, analisando-o minuciosamente para que não se cometa erros e consequentes injustiças afora toda e qualquer situação subjacente ao tema. Não obstante, torna-se de irrefutável valor a realização de uma completa anamnese, bem como o adequado diagnóstico do caso em questão por parte do cirurgião-dentista, sendo imprescindível que o mesmo informe ao paciente as opções disponíveis de tratamento bem como realize o preenchimento minudente do prontuário odontológico, além de arquivar cópias de atestados e receituários, exames radiográficos, modelos em gesso, orientações diversas (higienização, pós- operatório) e toda a documentação associada ao tratamento realizado, uma vez que todos os documentos supracitados possuem um importante valor probante em casos de lides judiciais.

\section{Referências}

1. ANTUNES FCM, DARUGE E, DARUGE JUNIOR E. O cirurgião dentista frente à responsabilidade civil. JAO Jornal de Assessoria ao Odontologista, v.4(9), p. 45-51, 2001.
2. AQUINO RG. Responsabilidade Civil do Cirurgião-Dentista. Noções Gerais e Competência da Justiça do Trabalho. LTr. Revista Legislação do Trabalho, São Paulo Brasil, Ano 73, nº 03, março, 2009.

3. CAIXETA FCTA. Da Responsabilidade Civil do Cirurgião-Dentista. In: Âmbito Jurídico, Rio Grande, n. 57, 2008.

4. CALVIELLI ITP. O Código de Defesa do Consumidor e o Cirurgião-Dentista como prestador de serviços. In: Silva $M$. Compêndio de odontologia legal. Rio de Janeiro: Medsi; 1997. p.391.

5. CAVALIERI FILHO S. Programa de Responsabilidade Civil, $9^{a}$ ed. São Paulo: Atlas, 2010.

6. DIAS RIBEIRO ARM. Erros profissionais e seus aspectos jurídicos em Odontologia legal. Rev. Bras. Odontol., Rio de Janeiro, v. 53(3), p. 41-43, 1996.

7. DINIZ MH. Curso de Direito Civil brasileiro, v.7 - 18. Ed. Ver. E atual. De acordo com o novo código civil (Lei $\mathrm{n}$. 10.406, de 10-1-2002) e o projeto de Lei $\mathrm{n}$. 6.960/2002. - São Paulo: Saraiva, 2004.

8.FELIX AFC, SOUZA AP. Responsabilidade civil médica e hospitalar. Belo Horizonte: Del Rey, 2001.

9.GONÇALVES CR. Direito Civil Brasileiro - Responsabilidade civil. vol.IV(6). São Paulo: Saraiva, 2010.

10.KFOURI NETO M. Responsabilidade civil do médico, $5^{\text {a }}$ edição, São Paulo, 2003, editora Revista dos Tribunais.

11.OLIVEIRA MLL. Responsabilidade civil odontológica. Belo Horizonte: Del Rey, 1999. 344 p.

12. PEREIRA W. A Responsabilidade Civil do Cirurgião-Dentista em face do Código de Defesa do Consumidor. Projeto $\mathrm{N}^{\circ} \mathrm{F}-002$. Faculdade Federal de Uberlândia. 2005. 
13. SOUZA NV. Breves considerações sobre a responsabilidade civil de dentistas. Proteção ao paciente. In: GORAB, R.; FELLER, C. Atualização na clínica odontológica: cursos antagônicos. São Paulo: Artes Médicas, 2000. p. 593-620.

14.STOCO R. Tratado de responsabilidade civil: doutrina e jurisprudência. 7 ed.. São Paulo Editora Revista dos Tribunais, 2007.

15.VENOSA SS. Direito civil: Responsabilidade Civil. 4. ed. São Paulo: Atlas, 2004. v. 4. 